\title{
PENEGAKAN HUKUM TERHADAP PELANGGARAN IZIN TRAYEK DI KABUPATEN MANGGARAI TENGAH
}

\author{
Mariano Roberto Solsepa, Ida Ayu Putu Widiati, I Putu Gede Seputra \\ Fakultas Hukum Universitas Warmadewa, Denpasar-Bali, Indonesia \\ rynosolsepa@gmail.com, widiati_dayu@yahoo.co.id, gamyongputu@gmail.com
}

\begin{abstract}
Abstrak
Sektor transportasi sangat penting dalam meningkatan mobilitas warga, maka tugas Dinas Perhubungan kabupaten Manggarai Tengah adalah menerbitkan izin penyelenggaraan angkutan orang dalam trayek berupa izin angkutan umum dan menertibkan angkutan umum yang tidak memiliki izin trayek. Penelitian ini bertujuan untuk menjelaskan efektivitas pengaturan izin trayek angkutan umum di Kabupaten Manggarai Tengah dan mengungkapkan upaya yang dilakukan Pemerintah Kabupaten Manggarai Tengah dalam penegakan angkutan umum yang tidak memiliki izin trayek. Metode yang digunakan dalam penelitian ini adalah penelitan hukum empiris dengan pendekatan sosiologis dan pendekatan fakta. Adapun sumber data yang digunakan adalah sumber bahan hukum primer dan sekunder yang diperoleh melalui pebcatatan dan dokumentasi, setelah semua data terkumpul selanjutnya dianalisis dengan kalitatif deskriptif. Hasil penelitian menunjukkan Pengaturan Izin Trayek di Kabupaten Manggarai Tengah dapat dikatakan kurang efektif mengingat masih banyaknya pelanggaran izin trayek angkutan umum. Upaya yang dilakukan dalam penegakan angkutan umum yang tidak memiliki izin trayek di Kabupaten Manggarai Tengah melakukan sosialisai terhadap pemilik jasa angkutan umum tentang pentingnya izin trayek angkutan umum.
\end{abstract}

Kata Kunci: Efektivitas Hukum, Izin Trayek, Pelanggaran Izin

\begin{abstract}
The transportation sector is very important in increasing the mobility of citizens, so the task of the Department of Transportation of Central Manggarai Regency is to issue permits for the operation of people's transportation on routes in the form of public transportation permits and regulate public transportation that does not have route permits. This study aims to explain the effectiveness of regulating public transport route permits in Central Manggarai Regency and to reveal the efforts made by the Central Manggarai Regency Government in enforcing public transport that does not have route permits. The method used in this research is empirical legal research with a sociological approach and a fact approach. The sources of data used are primary and secondary sources of legal materials obtained through records and documentation, after all the data has been collected and then analyzed using descriptive qualitative. The results of the study indicate that the regulation of route permits in Central Manggarai Regency can be said to be less effective considering that there are still many violations of public transport route permits. Efforts made in enforcing public transport that do not have a route permit in Central Manggarai Regency carried out socialization to owners of public transport services about the importance of public transport route permits.
\end{abstract}

Keywords: Legal Effectiveness, Route Permit, Permit Violation

\section{PENDAHULUAN}

Transportasi sangat penting dalam meningkatkan mobilitas warga, baik dari kepentingan umum maupun pelayanan perdagangan barang dan jasa, selain itu transportasi juga memiliki peranan penting bagi penunjang dan penggerak bagi pertumbuhan daerah yang berpotensi tetapi belum berkembang sebagai upaya peningkatan pemerataan pembangunan (Kartini, 2007) \& (Sutedi, 2011).

Angkutan umum sangat berguna bagi pengembangan perekonomian, oleh karena itu angkutan umum perlu membutuhkan penindakan keras. Angkutan sangat berguna bagi perekonomian lantaran selain kebutuhan jasa angkutan umum juga bisa mendistribusi barang dan tenaga kerja, juga menjadi poin dari perekonomian di kota (Silondae et al., 2016). Pembangunan di setiap daerah khususnya di Kabupaten Manggarai Tengah bertujuan untuk meningkatkan kesejahteraan masyarakat. Demikian pula dalam penanganan angkutan umum di Kabupaten Manggarai Tengah yang menjadi salah satu kewenangan Dinas Perhubungan, dimana Dinas Perhubungan Kabupaten Manggarai Tengah mempunyai fungsi dan wewenang melaksanakan sebagian peran disektor perhubungan atas dasar asas 
otonomi dan pembantuan tugas untuk daerah sesuai dengan ketentuan peraturan perundang-undangan yang berlaku. Dinas Perhubungan Kabupaten Manggarai Tengah bertanggung jawab terhadap pelayanan kepada masyarakat. Berkaitan dengan angkutan umum dan izin trayek angkutan umum tidak menutup kemungkinan terjadinya pelanggaran.

Perizinan angkutan umum bertujuan demi memberikan kepastian hukum dan hak untuk orang yang punya angkutan umum biar bisa kendaraan angkutannya beroperasi. Maksud dan tujuan memberikan izin trayek bagi kendaraan angkutan umum berdasarkan Perda Kabupaten Mang garai Tengah No.18 Tahun 2011 yakni mengatur kegiatan jasa usaha angkutan orang dalam trayek serta memberi legalitas kepada orang atau pribadi, badan usaha yang melaksanakan jasa pelayanan angkutan yang menjadi sasarannya adalah setiap orang maupun badan usaha atau badan hukum yang melakukan kegiatan dibidang usaha angkutan orang baik dalam trayek tertentu maupun yang tidak dalam trayek.

Ada beberapa penelitian terdahulu yang relevan dengan penelitian ini yaitu Simanjuntak, (2015) \& Rimbing et al., (2020) pemakaian angkutan tanpa izin merupakan perbuatan pelanggaran lalu lintas dan angkutan jalan, Jika pengemudi kendaraan bermotor umum yang tidak memiliki izin menyelenggarakan angkutan, akan dipidana dengan kurungan paling lama 2 (dua) bulan atau denda paling banyak Rp500.000,00. Upaya penegakan hukum dalam penanganan kasus ini yaitu dilakukan secara represif dengan memberi teguran dan peringatan kepada perusahaan angkutan sewa umum yang tidak memiliki izin operasional, dan apa bila tidak diindahkan maka diberi sanksi berupa penghentian kegiatan operasional angkutan sewa umum tersebut (Julisa et al., 2019).

\section{METODE PENELITIAN}

Jenis penelitian adalah penelitian hukum empiris artinya suatu penelitian yang mengkaji masalah berdasarkan fakta yang terjadi di lapangan, peneliti mengobservasi apa masalah yang sedang diteliti, selanjutnya dikaitkan dengan peraturan Perundang-undangan atau dengan kata lain yaitu penelitian yang dilakukan terhadap keadaan nyata yang terjadi di masyarakat dengan maksud untuk mengetahui dan menemukan fakta- fakta dan data yang dibutuhkan (Bambang, 2002) \& (Marzuki \& Mahmud, 2005). Orientasi pengkajiannya menitik beratkan pada kasus pelanggaran izin trayek yang ada di Kabupaten Manggarai Tengah. Pendekatan masalah adalah pendekatan sosiologis dan pendekatan fakta. Pendekatan sosiologis yaitu mengidentifikasi dan mengkonsepsikan hukum sebagai institusi sosial yang riil dan fungsional dalam bentuk kehidupan nyata (Soekanto, 1986). Adapun sumber bahan hukum yaitu bahan hukum primer dan sekunder yang diperoleh melalui teknik pencatatan dan dokumentasi. Setelah data terkumpul, selanjutnya dianalisis secara kulaitatif deskriptif

\section{HASIL DAN PEMBAHASAN}

\section{Efektivitas Pengaturan Izin Trayek Angkutan Umum di Kabupaten Manggarai Tengah}

Dinas perhubungan Kabupaten Manggarai Tengah memiliki peran pokok yaitu melakukan sebagian tugas Pemerintah dan pembangunan di bagian perhubungan khususnya retribusi izin trayek angkutan umum. Dari data yang diperoleh dari Dinas Perhubungan Kabupaten Manggarai Tengah jumlah kendaraan angkutan umum yang beroperasi di Kabupaten Manggarai Tengah sebagai berikut:

Tabel 3.1

Jumlah Kendaraan yang Beroperasi di Kabupaten Manggarai Tengah

\begin{tabular}{|c|c|}
\hline Tahun & Jumlah Kendaraan \\
\hline Tahun 2016 & 120 unit \\
\hline Tahun 2017 & 83 unit \\
\hline Tahun 2018 & 96 unit \\
\hline Tahun 2019 & 42 unit \\
\hline
\end{tabular}

Sumber: Dinas Perhubungan Kabupaten Manggarai Tengah 2020 
Berdasarkan penelitian observasi yang dilaksanakan di Dinas Perizinan Kabupaten Manggarai Tengah diperoleh data jumlah pemilik kendaraan angkutan umum yang tidak mengurus izin trayek dan tidak memiliki izin trayek angkutan umum sebagai berikut

Tabel 3.2

Angkutan Umum yang Tidak Mengurus Izin Trayek di Kabupaten Manggarai Tengah Dari Tahun 2016-2019

\begin{tabular}{|l|l|l|}
\hline \multirow{2}{*}{ Tahun } & \multicolumn{2}{|c|}{ Jenis Pelanggaran } \\
\cline { 2 - 4 } & $\begin{array}{l}\text { Angkutan Umum Yang Tidak Memiliki } \\
\text { Izin Trayek }\end{array}$ & $\begin{array}{l}\text { Angkutan Umum Yang Tidak Memperpanjang } \\
\text { Izin Trayek }\end{array}$ \\
\hline 2016 & 38 unit & 44 unit \\
\hline 2017 & 34 unit & 17 unit \\
\hline 2018 & 35 unit & 39 unit \\
\hline 2019 & 21 unit & 40 unit \\
\hline
\end{tabular}

Sumber: Dinas Perhubungan Kabupaten Managgarai Tengah 2020

Berdasarkan tabel di atas dapat diperoleh suatu analisa dimana masih banyaknya pelanggaran angkutan umum di Kabupaten Manggarai Tengah pada periode tahun 2016-2019, baik itu pelanggaran angkutan umum yang tidak memiliki izin trayek dan dan angkutan umum yang tidak memperpanjang izin trayek. Efektivitas hukum adalah suatu keberhasilan hukum untuk mencapai suatu tujuan. Efektivitas diartikan sebagai sesuatu atau kondisi di mana telah sesuai dengan pencapaian yang ditempuh atau diharapkan. Hukum itu dikatakan efektif apabila warga masyarakat berperilaku sesuai yang dikehendaki oleh hukum (Riza Alifianto Kurniawan, 2018). yakni:

Menurut pendapat Soerjono Soekanto tolak ukur efektivitas penegakan hukum ada lima hal

1. Faktor Hukum, hukum berlaku bagi keadilan, kepastian dan kemanfaatan.

2. Faktor penegakan hukum, dalam berfungsinya hukum mentalitas atau kepribadian petugas penegak hukum memainkan peranan penting kualitas petugas.

3. Faktor sarana atau fasilitas pendukung kerja aparat penegak hukum.

4. Faktor masyarakat, persoalan yang timbul adalah taraf kepatuhan hukum dari masyarakat,

5. Faktor kebudayaan, kebudayaan pada dasarnya mencakup nilai-nilai yang melandasi hukum yang berlaku.

Sarana penegakan hukum, selain pengawasan adalah sanksi. Sanksi sangatlah penting bagi peraturan Perundang-undangan. Bahkan J.B.J.M Ten Berge mengatakan kalau sanksi sangatlah inti dari penegakan administrasi (J.B.J.M Ten Berge 193:390) Sanksi biasanya diletakan pada akhir setiap peraturan. Menurut Hadjon, (1993) pada umumnya tidaklah penting memasukan kewajiban-kewajiban dan larang-larangan untuk warga di Peraturan Perundang-undangan Tata Usaha Negara, ketika aturan perilaku tersebut tidak dapat dipaksakan oleh Tata Usaha Negara. Salah satu instrumen untuk memaksakan perilaku para warga ini adalah sanksi. Maka dari itu, sanksi adalah salah satu yang melekat pada norma hukum tertentu.

\section{Upaya yang Dilakukan Pemerintah Kabupaten Manggarai Tengah dalam Penegakkan Angkutan Umum yang Tidak Memiliki Izin Trayek}

Penerapan Perda Kabupaten Manggarai Tengah No 18 Tahun 2011 tentang Retribusi Izin Trayek sangatlah sulit mengingat masih banyaknya jumlah pelanggaran angkutan umum yang terjadi. Dimana terdapat beberapa kendala yang dihadapi oleh Pemerintah Kabupaten Manggarai Tengah. Adapun 
kendala-kendala dalam penerapan izin angkutan umum seperti yang dijelaskan dalam wawancara dengan Paulus Y.M. Reme, SH. selaku Kepala Seksi Angkutan Jalan Dinas Perhubungan Kabupaten Manggarai Tengah pada tanggal 25 Februari 2020 dijelaskan bahwa banyaknya pelanggaran izin trayek di Kabupaten Manggarai Tengah dikarenakan:

1. Tidak adanya kesadaran pemilik kendaraan angkutan umum untuk mengurus izin trayek

2. Kurangnya pengetahuan masyarakat tentang prosedur mengajukan izin trayek angkutan umum.

3. Masih kurangnya kinerja aparat penegak hukum dalam menerapkan peraturan daerah tersebut.

Dari hasil penelitian yang dilakukan di Kabupaten Manggarai Tengah ada beberapa kendala yang menjadi faktor terjadinya pelanggaran izin trayek yakni :

1. Faktor pemerintah

Kurangnya sarana dan prasarana penunjang kerja di Dinas Perhubungan Kabupaten Manggarai Tengah seperti jumlah pegawai lapangan yang masih kurang, kinerja aparat hukum kualitas sumber daya manusia dalam penegakan hukum di Kabupaten Manggarai Tengah masih kurang seperti dalam penegakan aturan atau hukuman bagi pelanggar izin trayek belum efektif dan sosialisasi terhadap Peraturan Daerah yang masih kurang khususnya masalah izin trayek angkutan umum.

2. Faktor masyarakat

Perilaku masyarakat di Kabupaten Manggarai Tengah yang yang tidak taat akan peraturan pemerintah dan tidak memiliki kesadaran terhadap aturan pemerintah daerah.

Adapun upaya yang harus dilakukan oleh Pemerintah Daerah Kabupaten Manggarai Tengah dalam penegakan angkutan yang tidak memiliki izin trayek ataupun yang tidak memperpanjang izin trayek:

1. Pengembangan Pemeriksaan dan Pembinaan

Pengembangan pemeriksaan saat pengecekan, mampu menurunkan masalah bagi Dinas Perhubungan untuk menemui pemilik kendaraan angkutan umum yang masa berlaku izin trayeknya telah habis dan yang tidak memiliki izin trayek. Pengawasan saat pengecekan diberikan melalui peringatan lisan. Pembinaan dilakukan dengan memberikan penyuluhan atau sosialisasi tentang keamanan penumpang, berbagai izin yang wajib dipatuhi, serta yang berkaitan dengan wewenang Dinas Perhubungan. Dalam hal ini Dinas Perhubungan wajib berikan peringatan kepada pemilik angkutan umum yang melakukan pelanggaran.

2. Koordinasi Jadwal diawal Pembentukan Program

Razia dilakukan partisipasi bersama kepolisian agar bisa merazia bermacam-macam pelanggaran. Bukan cuma pelanggaran tentang izin trayek tetapi pelanggaran-pelanggaran lalu lintas. Adanya koordinasi waktu dan tanggal bersama kepolisian dalam penyusunan kegiatan sebagai cara Dinas Perhubungan Kabupaten Manggarai Tengah agar bisa mempererat partisipasi bersama kepolisian.

3. Monitoring dan Evaluasi

Monitoring dan Evaluasi dilakukan bukan cuma untuk sebuah program kegiatan tapi harus ada dana atau anggaran. Evaluasi bisa dilakukan memangkas berupa sebagian anggaran yang mungkin tidak perlu atau masih bisa digunakan. Sisa dari anggaran yang dipotong bisa dipakai untuk program kegiatan atau acara yang mungkin perlu. Maka harus dilakukan pemeriksaan ulang terhadap anggaran dana untuk berbagai kegiatan agar semua kegiatan bisa dijalankan sebaik-baiknya.

\section{SIMPULAN DAN SARAN \\ 1. Simpulan}

Berdasarkan uraian pembahasan terhadap permasalahan di atas maka dapat disimpulkan bahwa Pengaturan Izin Trayek di Kabupaten Manggarai Tengah dapat dikatakan kurang efektif mengingat masih banyaknya pelanggaran angkutan umum berupa angkutan umum yang tidak memiliki surat izin trayek dan angkutan umum yang tidak memperpanjang surat izin trayek di Kabupaten Manggarai Tengah yang disebabkan oleh aparat penegak hukum kurang tegas, kurangnya sosialisasi pemerintah kepada masyarakat atau pemilik angkutan umum tentang pentingnya memiliki surat izin trayek. Upaya yang dilakukan dalam penegakan angkutan umum yang tidak memiliki izin trayek di Kabupaten Manggarai Tengah, Menghimbau pemilik jasa angkutan umum harus menaati aturan yang sudah diberikan oleh petugas, melakukan sosialisasi terhadap pemilik jasa angkutan umum tentang pentingnya memiliki izin khususnya izin trayek angkutan umum, meningkatkan sarana dan prasarana petugas lapangan, masyarakat wajib mengawasi dan melaporkan angkutan umum yang tidak memiliki izin trayek ke Dinas Perhubungan Kabupaten Manggarai Tengah. 


\section{Saran}

Adapun saran yang dapat disampaikan yaitu Kepada pemerintah supauya menambah sarana dan prasarana untuk menunjang penegakan peraturan daerah di Kabupaten Manggarai Tengah seperti penambahan personil kerja di lapangan, dan meningkatkan kualitas sumber daya manusia aparat penegak hukum di Kabupaten Manggarai Tengah, serta dilakukan evaluasi terhadap kinerja perangkatnya. Dan kepada Dinas Perhubungan, Dinas Perizinan, dan Kepolisian melakukan koordinasi yang baik agar penegakan Perda No.18 Thn 2011 tentang Retribusi Izin Trayek dapat dilaksanakan dengan sebaik-baiknya. Agar pemilik jasa angkutan umum mematuhi Perda Kabupaten Manggarai Tengah No.18 Thn 2011 tentang Retribusi Izin Trayek, selain itu Pemerintah Kabupaten Manggarai Tengah baiknya terus melakukan sosialisasi tentang Perda Kabupaten Manggarai Tengah No.18 Tahun 2011 tentang Retribusi Izin Trayek, karena tidak semua masyarakat tahu apabila kendaraan ingin dijadikan angkutan umum harus mengurus izin trayek angkutan umum.

\section{DAFTAR PUSTAKA}

Bambang, W. (2002). Penelitian Hukum dalam Praktek. Jakarta: Sinar Grafika.

Hadjon, P. M. (1993). Penghantar Hukum Administrasi. University Press.

Julisa, Ardi, M., \& Rosdiana. (2019). Penegakkan Hukum terhadap Perusahaan Angkutan Sewa Umum yang Tidak Memiliki Izin Operasional di Kabupaten Penajam Paser Utara. Jurnal Lex Superma, 1(2), 1-14.

Kartini, R. (2007). Hukum Pengangkutan. Malang. Universitas Muhammadiyah

Marzuki, \& Mahmud, P. (2005). Penelitian Hukum. Jakarta. Kencana Prenada Media.

Rimbing, V. K. S., Rimbing, N., \& Karisoh, F. J. M. M. (2020). Pemberlakuan Ketentuan Pidana terhadap Pengemudi Kendaraan Bermotor Umum yang Tidak Memiliki Izin Menyelenggarakan Angkutan. Lex Crimen, 9(4), 133-142.

Riza Alifianto Kurniawan. (2018). Pencegahan Penyalahgunaan Kewenangan Penyidik dalam Penegakkan Hukum Tindak Pidana Narkotika. MJurnal Asalah - Masalah Hukum, 47(2), 111117.

Silondae, S., Muthalib, H. A. A., \& Ernawati. (2016). Keterkaitan Jalur Transportasi dan Interaksi Ekonomi Kabupaten Konawe Utara dengan Kabupaten/Kota Sekitarnya. Jurnal Progres Ekonomi Pembangunan, 1(1), 49-64.

Simanjuntak, H. M. (2015). Penegakan Hukum Pidana terhadap Pemilik Kendaraan Pribadi yang Dijadikan Angkutan Umum yang Tidak Memiliki Izin Trayek Berdasarkan Undang-undang Nomor 22 Tahun 2009 di Kabupaten Landak. Jurnal Gloria Yuris, 3(3), 1-12.

Soekanto, S. (1986). Kedudukan Janda Menurut Hukum Waris Adat. Jakarta: Ghalia Indonesia.

Sutedi, A. (2011). Hukum Perizinan dalam Sektor Pelayanan Publik. Jakarta. Sinar Grafika. 